\title{
EPIDEMIOLOGICAL STUDIES ON PROTEEAE ISOLATES FROM CLINICAL SPECIMENS IN THE LAQUINTINIE HOSPITAL IN DOUALA, CAMEROON
}

\author{
Kamga, H. L. F.* , Assob, J. C.N., Nsagha, D. S., Njunda, A. L. , Nde Fon P. and Tchape, G. N. E. \\ Faculty of Health Sciences, University of Buea, Republic of Cameroon \\ * Corresponding author: Dr Kamga Henri Lucien Fouamno, Faculty of Health Sciences, University of Buea, P.O Box, \\ 63, Buea, Cameroon, Phone number: (+237) 99721972. \\ E-mail: henrikamga2002@yahoo.fr
}

\begin{abstract}
The tribe Proteeae is a group of bacteria within the family Enterobacteriaceae and is responsible for most cases of nosocomial infections in hospital settings. The objective of this study was to determine the prevalence of members of Proteeae from clinical specimens in Laquintinie hospital in Douala. Specimens were collected from patients and screened for Proteeae using standard microbiological and biochemical methods (API 20 Enterobacteriaceae gallery). Of the 3414 clinical specimens made of 2712 urine, 264 blood, 243 CSF and 195 wounds and burns, 1136 (33.3\%) yielded a positive bacterial growth, of which $230(20.2 \%)$ were Gram positive and $906(79.7 \%)$ were Gram negative. 164 $(14.4 \%)$ isolates were identified as members of Proteeae of which 110(67.1\%) were from urine, 37( 22.6\%) from wounds and burns, 10(6.1\%) from blood and 7( 4.3\%) from CSF. Speciation of the Proteeae isolates showed that 111 (67.7\%) were Proteus mirabilis, 21(12.8\%) Proteus vulgaris, 11 (6.7\%) Providencia alcalifaciens, 6 (3.6\%) Providencia stuartii, 4 (2.4\%) Morganella morganii and 5 (3.0\%) Proteus penneri and Providencia rettgeri. There was a significant difference between the type of clinical specimens and the age of patients $\left(X^{2}=52.623 p<0.05\right)$. Most Proteeae isolates where susceptible to imipemen, ceftazidine, chloramphenicol, gentamicin, nalidixic acid, ofloxacin and amikacin. These findings have significant clinical and epidemiological implications.
\end{abstract}

Keywords: Proteeae isolates, Clinical specimens, Laquintinie Hospital, Cameroon

\section{INTRODUCTION}

The tribe Proteeae consists of a unique group of bacteria within the family Enterobacteriaceae. The genera include; The Enterobacteriaceae are Gram-negative, non-sporing rods measuring about $1-4 \times 0.6 \mu \mathrm{m}$. They are peritrichous and motile. Proteeae can be found in animals, soil and in the intestinal tract of humans. The Proteeae which include Proteus, Providencia and Morganella are unique among the Enterobacteriaceae in that, they have the ability to oxidatively deaminate a wide range of amino acids especially phenylalanine. Proteus, Providencia and Morganella are all oxidase negative and urease positive for some of their strains. They are readily isolated from pathological specimens [1]. Proteeae are of concern in that they have been involved in recent years with human infections, especially in the hospital areas. They have been readily isolated from urinary tract infections especially in patients with indwelling urinary catheters. They are thought to be responsible for almost $10 \%$ of nosocomial infections [2,3]. In addition, a number of Proteeae are often resistant to antibiotics commonly used in hospital practice and as such may facilitate their spread within this environment.
Mistry et al. [4] described high prevalence of Proteus mirabilis, in skin abscesses of the maxilla, which had potential implications for selection of antimicrobial therapy. A case of suppurative pericarditis caused by Proteus mirabilis and Citrobacter diversus were also identified [5] even though polymicrobial gram-negative infections in cases of pericarditis are known to be rare. Morganella morganii was found to be the sole potentially pathogenic bacterial species present in the feaces of some patients with diarrhea. Nosocomial infections outbreaks involving some strains of $M$. morganii are rare but are associated with serious morbidity and high mortality [1]. $M$. morganii has also been isolated from a patient with diabetic foot ulcer which resulted to a gas gangrene which was confounded with that caused by Clostridium [6]. M. morganii has also been responsible for the death of a 17 days termed neonate. Usually, it does not cause perinatal infection but will do in the immunocompromised patients and premature infants [7]. Providencia species occur in normal feaces and has been isolated from epidemic and sporadic cause of diarrhea in man though their importance in the causation of diarrhoeal disease 
is not easy to assess. However, Providencia rettgeri has been associated in cases of traveller's diarrhea in Japan [8]. They also cause UIT especially Pro. stuartii and Pro. rettgeri which are often hospital acquired [9]. Additionally, Pro. alcalifaciens has been reported in food borne infections outbreaks [10]. Generally, Providencia alcalifaciens is associated with infections of the intestinal tract and Providencia stuartii and Providencia rettgeri with infections of the urinary tract although exceptions do occur [1].

Epidemiological data on Proteeae isolates in clinical specimens and their antimicrobial sensitivity testing is important to help clinicians in the empirical selection of medications. In Cameroon, such data are scarce in healthcare settings due to dwindling resources and information used is usually from developed countries. The objective of this study was therefore to determine the prevalence of infections caused by organisms of the tribe Proteeae from clinical specimens in Douala Laquintinie hospital.

\section{MATERIALS AND METHODS}

\section{Study design and subjects}

This study was conducted in the Douala Laquintinie hospital, Cameroon, a tertiary health care hospital providing a full range of surgical, medical and super speciality facilities. The study was carried out from January to June 2010. All the subjects were patients sent to the bacteriology laboratory by physicians. There was no formal definition and recruitment was at the discretion of the attending physicians. However, prior to specimen collection, patients were explained the purpose of the study and made to understand that it was not a hospital obligation to participate in the research and neither was it a pre-requisite to accessing any hospital services publicly available. Patients' consent to participate was solicited. Ethical clearance was obtained from the Regional Delegation of Public Health.

\section{Bacteriological analysis}

Smears of the specimens were made and Gramstaining was also done to have an idea of the expected bacteria be it rod or cocci. For the urine samples, wet mount was made using the Mallassez counting chamber. Five bands were counted and multiplied by two to get the number of pus cells per cubic millimeter $\left(\mathrm{mm}^{3}\right)$. Specimens that had less than 5 pus cells $/ \mathrm{mm}^{3}$ cells were not cultured and those above were cultured. Specimens were plated on cysteinelactose-electrolyte-deficient (CLED) agar, Eosinmethylene blue (EMB) and blood agar. After overnight incubation at $37^{\circ} \mathrm{C}$, a representative of each type of oxidase Negative Non-lactose fermenting colony from the EMB and CLED agar were subcultured into peptone water and incubated at $37^{\circ} \mathrm{C}$ for a few hours. These were further inoculated on phenylalanine and urease agar slants and incubated overnight at $37{ }^{\circ} \mathrm{C}$. Proteeae isolates changed the phenylalanine agar to green. Further test were carried out for full identification. For blood Culture, about $10 \mathrm{ml}$ of patient's blood was added to Brain Heart Infusion Broth (BHI). The broth was incubated at $37^{\circ} \mathrm{C}$ and observed for growth on the $1^{\text {st }}, 2^{\text {nd }}, 3^{\text {rd }}$, $5^{\text {th }}, 8^{\text {th }}, 16^{\text {thand }} 21^{\text {st }}$ day. When positive growth was observed the broth was subcultured into blood and EMB agar.

All cultured plates were observed for colonial morphology of the bacteria such as size on agar, blood agar plates were used to detect swarming and hemolysis. The characteristic smell of Proteeae isolates was also noted. Oxidase test were performed on the non-lactose fermenting colonies using filter paper impregnated with a freshly prepare $10 \%$ solution of tetramethyl-pphenylene-diamine dihydrochloride. Proteeae isolates were purified alternatively on EMB agar before preservation. Purified colonies were maintained on nutrient agar slants at $4^{\circ} \mathrm{C}$ until used. Isolates were identified by their biochemical characteristics using the API 20 Enterobacteriaceae gallery (Biomérieux, France) as described by Cheesbrough[11].

The sensitivity of each identification test medium was confirmed by inoculating one or two uninoculated tubes of the batch alloy with the test medium inoculated with positive and negative control organisms. For the positive control, one of the test medium was inoculated with a stock culture of a bacterium (e.g a phenylalanine deaminase positive Proteus species) to give a positive reaction and another tube with stock culture known to give a negative reaction (e.g Escherichia coli ). These positive and negative controls were incubated at $37{ }^{\circ} \mathrm{C}$ and examined along site the alloy.

\section{Antibiotic susceptibility testing}

Single antibiotic impregnated disk were used with the following concentrations; amikacin $(10 \mu \mathrm{g})$, imipenem $(10 \mu \mathrm{g})$, ciprofloxacin $(5 \mu \mathrm{g})$, clotrimoxazole $(30 \mu \mathrm{g})$, tobramycin $(30 \mu \mathrm{g})$, chloramphenicol $(30 \mu \mathrm{g})$, ceftazidime $(10 \mu \mathrm{g})$, gentamicin $(10 \mu \mathrm{g})$, amoxycillin $(30 \mu \mathrm{g})$, ofloxacin $(10 \mu \mathrm{g})$, and nalidixic acid $(30 \mu \mathrm{g})$. Four to five colonies of identical morphology were emulsified into $3-4 \mathrm{ml}$ of sterile distilled water. The inoculum was prepared to meet the 0.5 McFarland standard (approximately $10^{8}$ microorganism per ml), (PML Microbiologicals, Inc, 2001). The prepared Mueller-Hinton agar plates were inoculated by streaking method using a swab of 
the inoculums. The plates were allowed to dry for 5 minutes to remove excess moisture. The antibiotic discs were then firmly placed on the inoculated plates using a flame sterile forceps. The discs were evenly distributed to allow an edge not less than $15 \mathrm{~mm}$ from the walls of the petridish. The inoculated plates were inverted and incubated aerobically at $37{ }^{\circ} \mathrm{C}$ for 24 hours. After overnight incubation, each plate was examined and the diameter of the complete inhibition zones were noted and measured with a caliper in millimeter. The inhibition zones were interpreted using the manufacturers standard table as being; susceptible (sensitive), intermediate or resistant.

A control test was done for the cultures since disc diffusion test vary with a number of experimental conditions and the organism in question. The control culture (E. coli) was plated simultaneously with the test culture and on separate plates. The zones of inhibition produced in the cultures by the same discs were compared.

Statistical analysis
Chi-square and t-test were used to test for the significance of the results obtained. $p<0.05$ was considered statistically significant.

\section{RESULTS}

All Proteeae isolates were phenylalanine positive. Only the Proteus isolates swarmed on blood and EMB agar at $37^{\circ} \mathrm{C}$ though a few strains did not. Of the urease positive isolates, the test results could be easily observed within 6 hours. Only $P$. mirabilis were indole negative. Some $P$. vulgaris strains were salicin and esculin positive. All isolates were oxidase negative, non-lactose fermenting colonies and gram negative rods.

A total of 3414 specimens were received from the hospital service areas of; Medical, Surgery, Pediatrics, Out-patients, Obstetrics and Gynaecology. Distribution of the clinical specimen by service area is shown in Table1. The largest number of wounds and burns were from the surgery wards, while most urine samples were from the out-patients and pediatrics services. There was no blood and cerebrospinal fluid (CSF) samples from obstetrics and gynaecology services.

TABLE 1: DISTRIBUTION OF CLINICAL SPECIMENS BY AREA OF MEDICAL SERVICE

\begin{tabular}{|c|c|c|c|c|c|c|}
\hline Service & Laboratory findings & Urine & Blood & $\begin{array}{l}\text { Wounds and } \\
\text { burns }\end{array}$ & CSF & Total \\
\hline \multirow[t]{3}{*}{ Surgery } & Samples & 57 & 12 & 96 & 9 & 174 \\
\hline & Bacterial isolates & 39 & 3 & 72 & 6 & 120 \\
\hline & Proteeae & 20 & 1 & 17 & 3 & 41 \\
\hline \multirow[t]{3}{*}{ Medicine } & Samples & 360 & 102 & 36 & 75 & 573 \\
\hline & Bacterial isolates & 177 & 36 & 12 & 18 & 243 \\
\hline & Proteeae & 36 & 0 & 9 & 0 & 45 \\
\hline \multirow[t]{3}{*}{ Pediatrics } & Samples & 726 & 126 & 6 & 108 & 966 \\
\hline & Bacterial isolates & 324 & 12 & 5 & 20 & 361 \\
\hline & Proteeae & 36 & 9 & 2 & 3 & 50 \\
\hline Obstetrics and & Samples & 150 & 0 & 12 & 0 & 162 \\
\hline \multirow[t]{2}{*}{ Gynaecology } & Bacterial isolates & 27 & 0 & 10 & 0 & 37 \\
\hline & Proteeae & 6 & 0 & 3 & 0 & 9 \\
\hline \multirow[t]{3}{*}{ Out -patients } & Samples & 1419 & 24 & 45 & 51 & 1539 \\
\hline & Bacterial isolates & 339 & 3 & 30 & 3 & 375 \\
\hline & Proteeae & 12 & 0 & 6 & 1 & 19 \\
\hline Total & & 2712 & 264 & 195 & 243 & 3414 \\
\hline
\end{tabular}

Table 2 shows the distribution of bacterial isolates by clinical source. There were 1136 bacterial isolates of which 230 (20.2\%) were Gram positive and 906 (79.7\%) were Gram negative. Of the Gram negative bacteria, 164 (18.1\%) were Proteeae isolates. The greatest number of bacterial isolates was from urine followed by wounds and burns. Staphylococcus aureus accounted for $114(49.6 \%)$ of the gram positive isolates. Most of the $18.1 \%$ Proteeae were from urine followed by wounds and burns then blood specimens. There was a significant difference between the bacterial species and the site of recovery, $\left(X^{2}=396.79 p<0.005\right)$. 
TABLE 2: CLINICAL SPECIMENS' SOURCE AND DISTRIBUTION OF BACTERIAL ISOLATES

\begin{tabular}{|c|c|c|c|c|c|}
\hline \multirow{2}{*}{ Bacterial isolates } & \multirow{2}{*}{ No. of isolates } & \multicolumn{4}{|c|}{ No. of bacteria isolates from } \\
\hline & & Wounds and burns & Urine & CSF & Blood \\
\hline Staphylococcus aureus & 114 & 11 & 84 & 8 & 11 \\
\hline Staphylococcus spp & 65 & 0 & 65 & 0 & 0 \\
\hline Streptococcus spp & 51 & 6 & 27 & 15 & 3 \\
\hline Klebsiella spp & 156 & 12 & 134 & 7 & 3 \\
\hline Escherichia coli & 453 & 18 & 427 & 0 & 8 \\
\hline Salmonella spp & 23 & 9 & 5 & 0 & 9 \\
\hline Enterobacter spp & 39 & 6 & 33 & 0 & 0 \\
\hline Proteeae & 164 & 37 & 110 & 7 & 10 \\
\hline Uncharacterized species & 71 & 30 & 21 & 10 & 10 \\
\hline Total & 1136 & 129 & 906 & 47 & 54 \\
\hline
\end{tabular}

$X 2=396.79 p<0.005$

Table 3 shows the frequency of isolation of Proteeae species from clinical specimens. Of the 164 Proteeae isolates, $111(67.7 \%)$ were made of $P$. mirabilis $21(12.8 \%)$ of $P$. vulgaris, $11(6.7 \%)$ of Providencia. alcalifaciens, 6 (3.6\%) of Pro. stuartii, 4 (2.4\%) of Morganella morganii and $5(3.0 \%)$ of $P$. penneri and Pro. rettgeri respectively. There was no significant difference between the species of
Proteeae isolated and the clinical specimens $\left(X^{2}=\right.$ 17.63, $p>0.05)$. The Distribution of Proteeae isolates by age in relation to clinical source is shown in Table 4. A greater number of Proteeae isolates were from the elderly aged 50 and above followed by the younger aged $0-10$ years, $\left(X^{2}=\right.$ $52.623 p<0.05)$.

\section{TABLE 3: FREQUENCY OF ISOLATION OF PROTEEAE SPECIES FROM CLINICAL SPECIMENS}

\begin{tabular}{|c|c|c|c|c|c|c|c|c|c|}
\hline \multirow[t]{2}{*}{ Source } & \multirow{2}{*}{$\begin{array}{l}\text { No of positive } \\
\text { bacteria } \\
\text { isolates }\end{array}$} & \multirow{2}{*}{$\begin{array}{l}\text { No (\%) of } \\
\text { Proteeae } \\
\text { isolates }\end{array}$} & \multicolumn{7}{|c|}{ Proteeae isolates identified } \\
\hline & & & $\begin{array}{l}P . \\
\text { mirabi } \\
\text { lis }\end{array}$ & $\begin{array}{l}P . \\
\text { vulga } \\
\text { ris }\end{array}$ & $\begin{array}{l}P . \\
\text { penne } \\
\text { ri }\end{array}$ & $\begin{array}{l}\text { Pro. } \\
\text { Stua } \\
\text { rtii }\end{array}$ & $\begin{array}{l}\text { Pro. } \\
\text { alcalifac } \\
\text { iens }\end{array}$ & $\begin{array}{l}\text { Pro. } \\
\text { rettg } \\
\text { eri }\end{array}$ & $\begin{array}{l}\text { M. } \\
\text { morga } \\
\text { nii }\end{array}$ \\
\hline $\begin{array}{l}\text { Wounds } \\
\text { and burns }\end{array}$ & 129 & $37(28.7)$ & 22 & 7 & 0 & 2 & 3 & 1 & 2 \\
\hline Urine & 906 & 110 (12.1) & 78 & 10 & 5 & 4 & 7 & 4 & 1 \\
\hline Blood & 54 & 10 (18.5) & 7 & 1 & 0 & 0 & 1 & 0 & 1 \\
\hline CSF & 47 & 7 (14.9) & 4 & 3 & 0 & 0 & 0 & 0 & 0 \\
\hline Total & 1136 & $164(14.4)$ & 111 & 21 & 5 & 6 & 11 & 5 & 4 \\
\hline
\end{tabular}

TABLE 4: DISTRIBUTION OF PROTEEAE ISOLATES BY AGE AND CLINICAL SPECIMENS

\begin{tabular}{llllll}
\hline Age (years) & Wounds and burns & Blood & Urine & CSF & Total \\
\hline $0-10$ & 4 & 9 & 55 & 6 & 74 \\
$11-20$ & 6 & 0 & 3 & 0 & 9 \\
$21-30$ & 6 & 1 & 2 & 0 & 9 \\
$31-40$ & 3 & 0 & 1 & 0 & 4 \\
$41-50$ & 8 & 0 & 15 & 0 & 23 \\
$>50$ & 10 & 0 & 34 & 1 & 45 \\
Total & 37 & 10 & 110 & 7 & 164 \\
\hline$X^{2}=52.623$ & $p<0.05$ & & & &
\end{tabular}

Table 5 shows the distribution of Proteeae species isolates by age of infected patients. In all, $P$. mirabilis accounted for 111 (67.7\%) of Proteeae species isolated. There was a significant level of association between age of patients and species distribution $\left(X^{2}=47.13 p<0.05\right)$.
$P$. penneri isolates were recovered mostly from the patients aged $0-10$ years. A greater number of Pro. rettgeri isolates were in the infected patients of age greater than 50 . 
TABLE 5: DISTRIBUTION OF PROTEEAE SPECIES ISOLATES BY AGE OF PATIENTS

\begin{tabular}{|c|c|c|c|c|c|c|c|c|}
\hline $\begin{array}{l}\text { Age } \\
\text { (years) }\end{array}$ & $\begin{array}{ll}\text { No of } \\
\text { isolates }\end{array}$ & P. mirabilis(\%) & $\begin{array}{l}P . \\
\text { vulgaris }\end{array}$ & $\begin{array}{l}P . \\
\text { penneri }\end{array}$ & $\begin{array}{l}\text { Prv. } \\
\text { stuartii }\end{array}$ & $\begin{array}{l}\text { Prv. } \\
\text { alcalifaciens }\end{array}$ & $\begin{array}{l}\text { Prv. } \\
\text { rettgeri }\end{array}$ & $\begin{array}{l}\text { M. } \\
\text { morganii }\end{array}$ \\
\hline $0-10$ & 74 & $48(64.9)$ & 7 & 5 & 3 & 8 & 1 & 2 \\
\hline $11-20$ & 9 & $4(44.4)$ & 3 & 0 & 1 & 1 & 0 & 0 \\
\hline $21-30$ & 9 & $3(33.3)$ & 4 & 0 & 1 & 0 & 1 & 0 \\
\hline $31-40$ & 4 & $2(50)$ & 2 & 0 & 0 & 0 & 0 & 0 \\
\hline $41-50$ & 23 & $15(65.2)$ & 5 & 0 & 0 & 2 & 0 & 1 \\
\hline$>50$ & 45 & $39(86.7)$ & 1 & 0 & 1 & 0 & 3 & 1 \\
\hline Total & 164 & 111 & 22 & 5 & 6 & 11 & 5 & 4 \\
\hline
\end{tabular}

Table 6 shows the frequency of Proteeae isolation from UTI's by service areas. From the surgery service, $20(51.3 \%)$ of Proteeae isolates caused urinary tract infections. Less Proteeae UTI's were noted in out-patients $12(3.5 \%)$ there were no marked significance of UTI's caused by Proteeae with respect to those caused by other bacteria in relation to various service areas $(t=1.43 p>0.05)$.
Table 7 shows the pattern of antimicrobial resistance among Proteeae isolates. Resistance to Tobramycin (TOB), Chloramphenicol (CMP), Gentamicin (GEN), and Nalidixic acid (NAL) were almost uniform. Pro. alcalifaciens, P. mirabilis and $P$. vulgaris presented some resistance to all the antimicrobial agents. There was marked resistance in Pro. rettgeri, $M$. morganii and Pro. stuartii, $\left(X^{2}=117.12 p<0.005\right)$.

TABLE 6: FREQUENCY OF PROTEEAE ISOLATION FROM URINARY TRACT INFECTIONS BY MEDICAL SERVICE AREA

\begin{tabular}{lll}
\hline Service & No of bacterial UTI cases & No (\%) of Proteeae \\
\hline Surgery & 39 & $20(51.3)$ \\
Medicine & 177 & $36(20.3)$ \\
Paediatrics & 324 & $36(11.1)$ \\
Obstetrics and Gynaecology & 27 & $6(22.2)$ \\
Out - patients & 339 & $12(3.5)$ \\
\hline Total & 906 & $110(12.1)$ \\
\hline
\end{tabular}

\section{DISCUSSION}

In the listing of gram-negative bacteria responsible for nosocomial infections, members of the tribe Proteeae are inclusive. The presence of Proteeae in clinical specimen is of great interest since like other Enterobacteriaceae they are opportunistic and may cause morbidity and motility [1].

In this study, gram-negative bacteria accounted for $79.7 \%$ of all isolates from clinical specimens examined and cultures in the medical microbiology laboratory. Gaynes and Edwards [12] in their surveillance study on nosocomial infections caused by gram-negative bacteria in intensive care units from a study period of 1986 to 2003 , found that gram negative bacteria caused $23.8 \%$ of blood stream infections, $33.8 \%$ of surgical site infections and $71.1 \%$ of urinary tract infections.
Clinical findings from this research also showed that after E. coli, Proteeae were the second group of bacteria recovered in this study. E. coli being the major bacteria species isolated is probably due to the existence of $E$. coli as a normal intestinal flora making its colonization of other parts of the body easier especially in cases of immune suppression. This is in agreement with previous findings [13] that E. coli accounts for the largest cause of cystitis, prostates and pyelonephritis in hospitals acquired infections. In another study [1], Proteus ranked third as the case of nosocomial infections in hospitals. From another study by De Champ et al.[14] Proteus ranked second after $E$. coli among enterobacteria responsible for nosocomial infections. In the present study, members of the tribe Proteeae were mostly recovered from urine samples. They have always been recognized as important cause of nosocomial urinary tract infections associated with long-term catheterization [13]. 
TABLE 7: PATTERN OF ANTIMICROBIAL RESISTANCE AMONG PROTEEAE ISOLATES

\begin{tabular}{|c|c|c|c|c|c|c|c|c|c|c|c|}
\hline $\begin{array}{l}\begin{array}{l}\text { Proteeae } \\
\text { species }\end{array} \\
\end{array}$ & TSU & GEN & AMK & TOB & NAL & OFX & CIP & AMO & IMI & CAZ & CMP \\
\hline $\begin{array}{l}\text { P. mirabilis } \\
\text { (111) }\end{array}$ & $\begin{array}{c}72 \\
(65)\end{array}$ & $\begin{array}{c}33 \\
(30)\end{array}$ & $15(13)$ & $\begin{array}{l}80 \\
(72)\end{array}$ & $\begin{array}{l}27 \\
(24)\end{array}$ & $\begin{array}{c}30 \\
(27)\end{array}$ & $\begin{array}{c}47 \\
(42)\end{array}$ & $43(39)$ & $\begin{array}{c}13 \\
(12)\end{array}$ & $\begin{array}{c}63 \\
(57)\end{array}$ & $\begin{array}{c}68 \\
(61)\end{array}$ \\
\hline $\begin{array}{l}\text { P. vulgaris } \\
\text { (21) }\end{array}$ & $\begin{array}{c}12 \\
(57)\end{array}$ & $\begin{array}{c}12 \\
(57)\end{array}$ & $8(26)$ & $9(42)$ & $\begin{array}{c}15 \\
(71)\end{array}$ & $\begin{array}{l}16 \\
(76)\end{array}$ & $\begin{array}{c}15 \\
(71)\end{array}$ & $\begin{array}{c}21 \\
(100)\end{array}$ & $\begin{array}{c}3 \\
(14)\end{array}$ & 4 (19) & $\begin{array}{l}19 \\
(90)\end{array}$ \\
\hline P. penneri (5) & $1(20)$ & $1(20)$ & $5(100)$ & $\begin{array}{c}5 \\
(100)\end{array}$ & $4(80)$ & 0 & 0 & $5(100)$ & $\begin{array}{c}3 \\
(60)\end{array}$ & $1(20)$ & $\begin{array}{c}5 \\
(100)\end{array}$ \\
\hline $\begin{array}{l}\text { Prv. stuartii } \\
\text { (6) }\end{array}$ & $1(17)$ & $\begin{array}{c}6 \\
(100)\end{array}$ & $1(17)$ & $\begin{array}{c}6 \\
(100)\end{array}$ & $4(67)$ & $3(50)$ & $2(33)$ & 0 & $\begin{array}{c}3 \\
(50)\end{array}$ & $2(33)$ & $\begin{array}{c}6 \\
(100)\end{array}$ \\
\hline $\begin{array}{l}\text { Prv. } \\
\text { alcalifaciens } \\
(\mathbf{1 1})\end{array}$ & $9(82)$ & $6(55)$ & $10(91)$ & $8(73)$ & $7(64)$ & $7(64)$ & $9(82)$ & $\begin{array}{c}11 \\
(100)\end{array}$ & $\begin{array}{c}3 \\
(27)\end{array}$ & $3(27)$ & $\begin{array}{c}10 \\
(91)\end{array}$ \\
\hline $\begin{array}{l}\text { Prv. rettgeri } \\
\text { (5) }\end{array}$ & $1(20)$ & $4(80)$ & $4(80)$ & $\begin{array}{c}5 \\
(100)\end{array}$ & $\begin{array}{c}5 \\
(100)\end{array}$ & $4(80)$ & $\begin{array}{c}5 \\
(100)\end{array}$ & $5(100)$ & $\begin{array}{c}2 \\
(40)\end{array}$ & 0 & $\begin{array}{c}5 \\
(100)\end{array}$ \\
\hline $\begin{array}{l}\text { M. morganii } \\
\text { (4) }\end{array}$ & $\begin{array}{c}4 \\
(100)\end{array}$ & $2(50)$ & $2(50)$ & $2(50)$ & $\begin{array}{c}4 \\
(100)\end{array}$ & $\begin{array}{c}4 \\
(100)\end{array}$ & $\begin{array}{c}2 \\
(50)\end{array}$ & $4(100)$ & 0 & 0 & $\begin{array}{c}4 \\
(100)\end{array}$ \\
\hline
\end{tabular}

$X^{2}=117.12 p<0.005 \mathrm{AMK}$, Amikacin; IMI, Imipenem; CIP, Ciprofloxacin; TSU, Clotrimoxazole; TOB, Tobramycin; CMP, Chloramphenicol; CAZ, Ceftazidime; GEN, Gentamicin; AMO, Amoxycillin; OFX, Ofloxacin; NAL, Nalidixic acid.

The predominance of Proteus among all the Proteeae is consistent with previous reports [1, 14]. Apart from urine specimens being the source of most clinical isolates of Proteeae, others were recovered from wounds and burns, followed by blood and the least in CSF. P. mirabilis was recovered more often than $P$. vulgaris especially in UTIs. The predominance of $P$. mirabilis in UTIs is related to its specific pathogenic ability. It has the potentials to colonize the urinary tract by tolerating the local $\mathrm{pH}$ and swarm by the aid of fimbriae. $P$. mirabilis also has the ability to evade host defenses by producing IgA which degrade protease and finally damaging the host tissue with urease and hemolysins [15,16,17]. According to the Center for Disease Control [18], Proteus is responsible for $3 \%$ of nosocomial infections in American hospitals.

From this study the significance on the distribution of Proteeae isolates related to age was explicit. Recovery of Proteeae isolates was mostly from urine of patients aged $0-10$ and $>50$ years. The young have a less developed immune system and for the elderly a system that warns out with time. Age specific infections rate could also be due to the fact that $P$. mirabilis mostly infects host compromised by underlying diseases or abnormalities. The elderly patients have increased risk factors predisposing them to infections by Proteeae. Risk factors like impaired host defense which occurs in cases of underlying diseases. Though macrophages and polymorphonuclear leukocytes functions are not affected by age, the quality and quantity of antibodies produced by B-cells are jeopardized thus increasing susceptibly to bacterial infections.

CSF and blood are generally sterile in nature, but the presence of any microbe is indicative of infection and polymicrobes implies contamination during laboratory culture procedures. Isolation frequency of Proteeae isolates from blood samples of patients according to age revealed that patients aged 0-10 years had the highest rate of infection. Neonates are generally easily infected by various bacteria at birth. This is due to the nature of the vagina at pregnancy which favors replication of bacteria. As such during birth the neonate becomes infected at the level of the birth canal. Ovalle et al. [7] reported $M$. morganii to be the cause of sepsis in premature infant and a cefotaxime resistant sepsis in a 17 days neonate infected at birth. Other factors could have well been responsible for sepsis in patients age 0-10 years caused by Proteeae.

Proteeae bacteremia in the elderly $(>50)$ may be associated to operative procedures on the lower urinary tract which requires the use of urinary catheters. Bacteremia may be provoked 
immediately after surgery or by delayed removal or change of the catheter. Patients with long-term indwelling urinary catheters usually have bacteriuria and sometimes bacteremia[13]. Underlying urethral abnormalities, type of catheter and bacteriocins in urine may have an influence on bacteremia [19].

From this study, Providencia species were responsible for $13,6 \%$ of urinary tract infections which is comparatively less than that proposed $(18 \%)$ in a Canadian study [9]. Providencia bacteriuria in the hospital settings of the united states are rare that is; $0.3-1 \%$ which denotes a good reduction in their cause of nosocomial infections [20]. Also Koreishi et al. [21] have shown that Providencia spp could be responsible for $6.33 \%$ of blood stream infections. But from this study $10 \%$ Providencia were recovered from patients with blood sepsis, which however was not significant.

In this study, from the four M. morganii isolates recovered two were from wounds and burns and the others from urine and blood. Recovery of $M$. morganii in wounds and burns is consistent with previous findings [6] in which this organism was isolated from a diabetic foot ulcer. M. morganii infections are uncommon but easily observed in HIV/AIDS patients, neonates and the elderly. The significant relationship between Proteeae species and the age range group in this study shows that there was a high percentage of $P$. mirabilis from patients age $0-10$ years followed by those $>50$ years. This is in accord with another report [1]. P. penneri was obtained in urine of patients aged 0-10 years; and it was probably due to contamination of the urinary tract by feacal residues, since $P$. penneri had always, in the past, been associated with outbreaks of diarrheal infections and kidney stones formation. The high rate of recovery of Proteeae from patients in the surgery service and urinary tract infections explains the fact that most patients may have just been cross contaminated. Infection may have resulted from improperly sterilized equipments, contaminated sterile surgery material, infected personnel and environmental factors such as bedding and post- surgery catheters.

In this study, of a total of 1539 samples obtained from out-patients, only $19(0.01 \%)$ Proteeae isolates were recovered. This indicates that Proteeae species in out-patients may have also resulted from specimen contamination or patients' contamination on their passage in the consultation room. Such assumption suggests the possibility of cross-infection presumably from contaminated or unsterilized equipments.

Most Proteeae isolates obtained in this study where susceptible to imipenem, ceftazidime, chloramphenicol, gentamicin, nalidixic acid, ofloxacin and amikacin. P. mirabilis and Pro. alcalifaciens were readily distinguished by their marked susceptibility to the eleven antimicrobials. Pro stuartii was found to be $100 \%$ resistant to gentamicin, tobramycin and chloramphenicol but had marked susceptibility to ciprofloxacin and ceftazidime. Spach et al.[22] explained that there have been decrease in the susceptibility of ciprofloxacin due to its routine usage. Prominent resistance was also observed in Pro. rettgeri to tobramycin, naldixic acid, ciprofloxacin, amoxicillin and chloramphenicol. This observation is in conformity to findings from O'Hara et al. [1]. According to this author, Pro. rettgeri resistance to tobramycin and gentamicin could be attributed to excessive usage of these drugs. Biedenbach et al. [23] also studied the susceptibility of Proteeae organisms to gentamicin, imipenem, ciprofloxacin, tobramycin and found similar the results with those of this study.

To determine the epidemiological patterns of Proteeae infections in the different service areas, Dienes test for colony compatibility was done. Strains involved in cross-infection in the surgery, medicine and out-patients department were detected. Results suggested that Dienes reactions could be due to bacteriocin- like substances. Dienes phenomenon can easily be observed when clinical isolates are labeled with fluorescent proteins, but however can be mediated by UV light or bacteriocins [24]. Dienes compatibility strains are to some extent related. Colony compatible strains observed in this study could have been due to case to case transmission as a result of inadequate nursing techniques in these service areas. Dienes positive reactions could be taken as indication that the strains were different while Dienes negative reactions should not be taken as a reliable test of identification. However Dienes reaction was the criterion used to determine strains involved in nosocomial cross infection in this research.

Lack of full information on patient's history (sex, duration of hospitalization, medical prescription and clinical syndrome) and poor specification on urine sample collection are some of the limitations of this study. Knowledge on catheterized and non-catheterized urine would have been an essential parameter for prevalence studies.

\section{Conclusion}

There was variability in the frequency of isolation of Proteeae from clinical specimens. In this study, the Proteeae isolates were obtained from urine, wounds and burns, blood and CSF. Of the bacterial isolates obtained from specimens in this 
research, $18.1 \%$ were caused by Proteeae species of which $P$. mirabilis was predominant, followed by $P$. vulgaris and Pro. alcalifaciens. $P$. penneri are rarely isolated from clinical specimens but in this research five were isolated. Most Proteeae isolates were obtained from urine clinical samples. Epidemiological patterns of Proteeae infections in the service areas showed that most isolates were from in-patients with the least from out-patients. High prevalence of Proteeae infections was probably due to the extended time of hospitalization and the overcrowding nature of the wards. All Proteeae isolates from this study exhibited resistance to antibiotics commonly used in hospitals. However, they were susceptible to ceftazidime, ofloxacin, nalidixic acid, ciprofloxacin and gentamicin. Pro. stuartii, Pro. rettgeri, $P$. vulgaris were readily resistant to

\section{REFERENCES}

1. O'Hara CM, Brenner FW, Miller JM (2000): Classification, identification, and clinical significance of Proteus, Providencia, and Morganella. Clin. Microbiol. Rev.13: 534-546.

2. Emori GT, Gaynes RP(1993): An overview of nosocomial infections, including the role of the microbiology laboratory. Clin Microbiol Rev. 6: 428.

3. Zeamanuel T. (2007). Hospital acquired infections and catheter related urinary tract infections amongst admitted patients in the Mekele hospital in Ethiopia. MSc. Thesis, Addis Ababa University, Ethiopia. p27.

4. Mistry RD, Scott HF, Alpern ER, Zaoutis TE. (2010). Prevalence of Proteus mirabilis in skin abscesses of the axilla. $J$ Pediat 56 (5): 850-1.

5. Sawaya, Fadi J; Sawaya, Jaber I; Gharzuddine, Walid; Eid, Elias V; Kanj, Souha S. (2009). Polymicrobial gramnegative pericarditis. Intern I Infect Dis. 13(6): 483-4.

6. Sujoy G, Abhijit MB, Malik I, Collier A. (2009). Fatal Morganella morganii bacteraemia in a diabetic patient with gas gangrene. J Med. Microbiol. 58: 965967.

7. Ovalle A, Angelica MM, Kakarieka E, Mirna G, Abril S. (2009). Early-onset sepsis due to Morganella morganii. Revista Medica de Chile. 137 (9): $1201-$ 1204.

8. Yao JDC, Moellering Jr. RC (1999). Antibacterial agents. In PR Murray et al. (ed.), Manual of clinical microbiology, 7th ed. American Society for Microbiology, Washington, D.C. pp1474-1504.

9. Nicolle LE (2001). Urinary tract pathogens in complicated infection and antibiotics comparatively to P. mirabilis and Pro. alcalifaciens which were easily susceptible to antimicrobials. M. morganii, Pro. stuartii and $P$. penneri were the Proteeae most resistant to antimicrobials.

There was evidence of nosocomial cross-infection especially in the medical and surgical services of the hospital. The control of nosocomial infections caused by Proteeae requires constant surveillance on their epidemiological profile and the routine usage of antimicrobials in hospitals.

\section{ACKNOWLEDGEMENTS}

The management and staff of the Laquintinie Hospital in Douala, Cameroon are hereby appreciated for permitting and participating in this study.

in elderly individuals. Journ Infec. Dis 183 Suppl 1:S5-8.

10. Murata $T$, Iida $T$, Shiomi $Y$, Tagomori $K$, Akeda Y, Yanagihara I, et al. A large outbreak of foodborne infection attributed to Providencia alcalifaciens. J Infect Dis 184 (8): 1050-5.

11. Cheesbrough M (2006). District Laboratory Practice in Tropical countries. 2th Edition, Cambridge University Press.

12. Gaynes R, Edwards JR (2005). Overview of nosocomial infections caused by gram-negative bacilli. Clin Infect Dis. 41(6): 848-54.

13. Stamm WE (1999). Urinary tract infections. In RK Root (ed.), Clinical infectious diseases: a practical approach. Oxford University Press, Inc. p. 649-656.

14. De Champs C, Sirot D, Chanal C, Sirot J and French Study Group (1999). A survey of extended-spectrum Blactamase in Enterobacteriaceae in France. In Program and Abstracts of the Thirty-Ninth Interscience Conference on Antimicrobial Agents and Chemotherapy, San Francisco, CA, 1999. Abstract 1485, p. 168. American Society for Microbiology, Washington, DC.

15. Johnson DE, Russell RG, Lockatell CV, Zulty JC, Warren JW, Mobley HL (1993). Contribution of Proteus mirabilis urease to persistence, urolithiasis, and acute pyelonephritis in a mouse model of ascending urinary tract infection. Infect Immunol. 61(7): 2748-54.

16. Walker KE, Moghaddame-Jafari S, Lockatell CV, Johnson D, and Belas R.(1999). ZapA, the IgA-degrading metalloprotease of Proteus mirabilis, is a virulence factor expressed specifically in swarmer cells. Mol Microbiol. 32(4): 
17. Jansen AM., Lockatell CV., Johnson DE. and Mobley HLT. (2003). Expression of Mannose-Resistant/Proteus-Like

$(\mathrm{MR} / \mathrm{P}) \quad$ Fimbriae Mediates Autoaggregation and Localization of Proteus mirabilis to the Bladder Surface During Ascending Urinary Tract Infection. Infect Immunol. 72(12): 72947305

18. Centers for Disease Control and Prevention. (1996). National nosocomial infections surveillance (NNIS) report, data summary October 1986-April 1996. American J Infect Cont. 24: 381.

19. Yuyun MF, Angwafo III FF, KoullaShiro S, Zoung-Kanyi J. (2004). Urinary Tract Infections in Cameroonian men. Tropical Medicine and International Health. Volume 9 no 4. Blackwell Publishing Ltd. pp 520-525.

20. Rahav G, Pinco E, Silbaq F, Bercovier H.(1994) Molecular epidemiology of catheter-associated bacteriuria in nursing home patients. J Clin Microbiol. 32 (4): 1031-4.

21. Koreishi AF, Schechter BA, Karp CL. (2006) Ocular infections caused by Providencia rettgeri. Ophthalmology 113(8):1463-6.

22. Spach, D. H., and W. C. Liles. (1999). Antimicrobial therapy for bacterial diseases. In R. K. Root (ed.), Clinical infectious diseases: a practical approach. Oxford University Press, Inc., New York, N.Y; p. 337-348

23. Biedenbach DJ, Jones RN, Erwin ME (1993). Interpretive accuracy of the disk diffusion method for testing newer orally administered cephalosporins against Morganella morganii. J Clin Microbiol. 31: 2828- 2830.

24. Budding $\mathrm{AE}$, Ingham $\mathrm{CJ}$, Bitter $\mathrm{W}$, Vandenbroucke-Grauls CM, Schneeberger PM. (2009).The Dienes Phenomenon: Competition and Territoriality in Swarming Proteus mirabilis. J Bacteriol. 191(12): 3892-3900. 